\title{
Fabrication and Surface-Modification of Silica/Gadolinium Compound/Silica Core-Shell Nanoparticles
}

\author{
Eriko Kawamata, Tomoya Inose, Yoshio Kobayashi \\ Department of Biomolecular Functional Engineering, College of Engineering, Ibaraki University \\ 4-12-1 Naka-narusawa-cho, Hitachi, Ibaraki 316-8511, Japan \\ aqua-sea.sky-wind@docomo.ne.jp; 16nm5121@vc.ibaraki.ac.jp; yoshio.kobayashi.yk@vc.ibaraki.ac.jp
}

\begin{abstract}
The present work describes methods for fabricating multilayered core-shell nanoparticles composed of silica $\left(\mathrm{SiO}_{2}\right)$ as a core, gadolinium compound $(\mathrm{GdC})$ as an inner shell, and $\mathrm{SiO}_{2}$ as an outer shell $\left(\mathrm{SiO}_{2} / \mathrm{GdC} / \mathrm{SiO}_{2}\right)$, and for surface-modifying the $\mathrm{SiO}_{2} / \mathrm{GdC}_{\mathrm{SiO}}$ nanoparticles. $\mathrm{SiO}_{2}$ nanoparticles with an average size of $28.6 \pm 12.6 \mathrm{~nm}$ were produced by a sol-gel method using tetraethylorthosilicate (TEOS) and methylamine in water/ethanol solution. GdC-coated $\mathrm{SiO}_{2}$ nanoparticles $\left(\mathrm{SiO}_{2} / \mathrm{GdC}\right)$ with an average particle size of $107.0 \pm 23.0 \mathrm{~nm}$ and an average $\mathrm{GdC}$ shell thickness of $35.9 \pm 4.9 \mathrm{~nm}$ were synthesized by a homogeneous precipitation method at $80^{\circ} \mathrm{C}$ in water/propanol solution containing $\mathrm{Gd}\left(\mathrm{NO}_{3}\right)_{3}$, urea and polyvinylpyrrolidone in the presence of the $\mathrm{SiO}_{2}$ nanoparticles. Succeeding $\mathrm{SiO}_{2}$-coating of the $\mathrm{SiO}_{2} / \mathrm{GdC}$ nanaoparticles was performed by using TEOS and $\mathrm{NaOH}$ in the presence of $\mathrm{SiO}_{2} / \mathrm{GdC}$ nanoparticles. Consequently, $\mathrm{SiO}_{2} / \mathrm{GdC} / \mathrm{SiO}_{2}$ nanoparticles with an average particle size of $119.0 \pm 39.0 \mathrm{~nm}$ and an average $\mathrm{SiO}_{2}$ shell thickness of $8.5 \pm 2.7 \mathrm{~nm}$ could be obtained. The $\mathrm{SiO}_{2} / \mathrm{GdC}_{\mathrm{SiO}}$ nanoparticles were successfully surface-modified by using 3 -aminopropyltrimethoxysilane for amination, and by followingly using succinic anhydride for carboxylation.
\end{abstract}

Keywords: Multilayer, Core-shell, Nanoparticle, Silica, Gadolinium, Sol-gel, Homogeneous precipitation, Surfacemodification.

\section{Introduction}

Because of magnetic resonance based on paramagnetism of gadolinium $(\mathrm{Gd})$ ions, they function to increase contrast of images taken by a magnetic resonance imaging (MRI) technique [1]. Commercially-available Gd ion-related MRI contrast agents are solutions dissolving the Gd complexes homogeneously at molecular level. The contrast agents injected into living bodies flow in living bodies, and finally are discharged out of the living bodies. Since Gd complex molecules are smaller than the particles, their velocity may be large compared to nano- or submicron particles, which provides small drag force given from fluid. Thus, the discharge for the Gd complex molecules is quick, which makes it difficult to take high contrast images for a long period.

Particles containing Gd compounds (GdC) are promising as a new MRI contrast agent. The particles, which are larger than Gd ion-related molecules, are dragged from fluid to a direction opposite to the fluid due to their projected area larger than molecules, so that they can be expected to stay in living bodies for a long period due to controlled flow of the particles in liquid. Consequently, formation of the particles containing $\mathrm{GdC}$ will increase residence time of GdC in the living bodies, which makes it possible to take clear MRI images for a long term. The particles are required to unaggregate in living bodies, because aggregation of the particles increases their apparent size, which prevents them from flowing in body fluid. Since surface of silica $\left(\mathrm{SiO}_{2}\right)$ particles prepared by a sol-gel method has a feature of colloidal stability, $\mathrm{SiO}_{2}$ particles containing GdC may function as the MRI contrast agent that shows long residence time and non-aggregation in living bodies.

Because strong interaction between water protons and GdC molecules promotes MRI properties of GdC [2], the GdC is desired to be present on or near surface of $\mathrm{SiO}_{2}$ nanoparticles containing GdC. The GdC on or near the particle surface may release free gadolinium ions through dissociation of the complexes. The release of gadolinium ions may provoke adverse reactions in some patients [3], though their toxicity is lower than that of iodine compounds. As one of methods for reducing the adverse reactions derived from GdC, coating of GdC surface with materials inert to living bodies as shell can be given, because contact of the $\mathrm{GdC}$ with living bodies may be controlled with a physical barrier of the shell materials. The $\mathrm{SiO}_{2}$ is a candidate as the shell materials because of its inertness to living bodies. From this view point, our research 
group has reported the fabrications of core-shell nanoparticles composed of core of $\mathrm{SiO}_{2}$ and shell of $\left.\mathrm{GdC}_{(\mathrm{SiO}} / \mathrm{GdC}\right)$, and of multilayered core-shell nanoparticles composed of core of $\mathrm{SiO}_{2} / \mathrm{GdC}$ nanoparticles and shell of $\mathrm{SiO}_{2}$ $\left(\mathrm{SiO}_{2} / \mathrm{GdC} / \mathrm{SiO}_{2}\right)$ [4]. The core-shell nanoparticles have another advantage. The $\mathrm{GdC}$ inside the particles can not function as the MRI contrast agent well, because it can not contact the protons in water. Thus, if the inside of the particles is replaced with core nanoparticles other than the $\mathrm{GdC}$, the replacement will decrease the production cost of MRI contrast agent nanoparticles.

To use the MRI contrast agent nanoparticles practically, functional molecules such as polyethyleneglycol and antibody protein should be immobilized onto the particles for avoiding the particles from being recognized as foreign materials in living bodies and delivering the particles to antigen proteins due to a good affinity between the antibody proteins and the antigen proteins, respectively. Prior to the immobilizations, the particles are desired to be surfacemodified with functional groups such as amino group and carboxylic group, because some functional molecules are attracted to these functional groups electro-statically or many kinds of chemicals react with the functional groups. The present paper describes methods for fabricating $\mathrm{SiO}_{2} / \mathrm{GdC} / \mathrm{SiO}_{2}$ nanoparticles, and for surface-modifying $\mathrm{SiO}_{2} / \mathrm{GdC} / \mathrm{SiO}_{2}$ nanoparticles toward a precursor of MRI contrast agent nanoparticles on which various functional molecules are immobilized.

\section{Experimental}

\subsection{Preparation of Nanoparticles}

A colloid solution of $\mathrm{SiO}_{2}$ nanoparticles was prepared by a sol-gel method using tetraethylorthosilicate (TEOS) as a $\mathrm{SiO}_{2}$ source and methylamine (MA) as a catalyst. A solution of TEOS and ethanol was added to a solution of MA, water and ethanol under stirring in a hermetically sealed flask with a magnetic stirrer. The reaction temperature and time were $35^{\circ} \mathrm{C}$ and $24 \mathrm{~h}$, respectively. Initial concentrations of TEOS, $\mathrm{H}_{2} \mathrm{O}$ and $\mathrm{MA}$ were $0.2,20$, and $0.018 \mathrm{M}$, respectively. The silica nanoparticles were washed by repeating centrifugation, removal of supernatant, addition of the water and sonication over three times. GdC-coating of $\mathrm{SiO}_{2}$ nanoparticles, or fabrication of $\mathrm{SiO}_{2} / \mathrm{GdC}$ nanoparticles was performed by a homogeneous precipitation method in the presence of the washed silica nanoparticles. The colloid solution of washed $\mathrm{SiO}_{2}$ nanoparticles and polyvinylpyrrolidone (PVP) dissolved in 1-propanol were added to a water/1-propanol solution, and the mixture was aged for $24 \mathrm{~h}$ at room temperature under stirring in a hermetically sealed flask with a magnetic stirrer. A urea aqueous solution was added to the aged mixture, and then $\mathrm{pH}$ of the mixture was adjusted to 5 by adding nitric acid. $\mathrm{A} \mathrm{Gd}\left(\mathrm{NO}_{3}\right)_{3}$ aqueous solution was added to the mixture. The mixture was aged for $3 \mathrm{~h}$ at $80^{\circ} \mathrm{C}$ under stirring. Initial concentrations were $0.001 \mathrm{vol} \% \mathrm{SiO}_{2}, 1 \mathrm{~g} / \mathrm{L} \mathrm{PVP}, 0.5 \mathrm{M}$ urea and 0.001 $\mathrm{M} \mathrm{Gd}\left(\mathrm{NO}_{3}\right)_{3}$, and a volume ratio of water : 1-propanol was 1 : 1 . $\mathrm{SiO}_{2}$-coating of $\mathrm{SiO}_{2} / \mathrm{GdC}$ nanoparticles, or fabrication of $\mathrm{SiO}_{2} / \mathrm{GdC}_{\mathrm{SiO}}$ nanoparticles was performed by a sol-gel method using TEOS as a $\mathrm{SiO}_{2}$ source and $\mathrm{NaOH}$ as a catalyst. The TEOS and a $\mathrm{NaOH}$ aqueous solution were added to the as-prepared colloid solution of $\mathrm{SiO}_{2} / \mathrm{GdC}$ nanoparticles under stirring in a hermetically sealed flask with a magnetic stirrer. The reaction temperature and time were $35^{\circ} \mathrm{C}$ and $24 \mathrm{~h}$, respectively. Initial concentrations of TEOS and $\mathrm{NaOH}$ were 0.013 and $0.002 \mathrm{M}$, respectively.

\subsection{Surface-Modification of Nanoparticles}

The $\mathrm{SiO}_{2} / \mathrm{GdC}_{\mathrm{SiO}}$ nanoparticles were surface-modified with amino groups by a reaction between an alkoxide group of (3-aminopropyl)trimethoxysilane (APMS) and hydroxide groups of the $\mathrm{SiO}_{2}$ surface on $\mathrm{SiO}_{2} / \mathrm{GdC} / \mathrm{SiO}_{2}$ nanoparticles $\left(\mathrm{SiO}_{2} / \mathrm{GdC} / \mathrm{SiO}_{2}-\mathrm{NH}_{2}\right)$. The APMS was added to the as-prepared colloid solution of $\mathrm{SiO}_{2} / \mathrm{GdC}_{\mathrm{SiO}}$ nanoparticles. The reaction temperature and time were $35^{\circ} \mathrm{C}$ and $24 \mathrm{~h}$, respectively. An initial APMS concentration was $0.03 \mathrm{M}$. The $\mathrm{SiO}_{2} / \mathrm{GdC} / \mathrm{SiO}_{2}-\mathrm{NH}_{2}$ nanoparticles were washed by repeating centrifugation, removal of supernatant, addition of solvent and sonication over two times. The solvents used in the second and the third washing processes were 1-propanol and dimethylformamide (DMF), respectively, which provided the replacement of solvent of colloid solution with DMF. According to the reference [5], the amino groups on $\mathrm{SiO}_{2} / \mathrm{GdC} / \mathrm{SiO}_{2}-\mathrm{NH}_{2}$ nanoparticles were transformed to carboxyl groups by a reaction between a functional group of succinic anhydride (SA) and the amino group on $\mathrm{SiO}_{2} / \mathrm{GdC} / \mathrm{SiO}_{2}-\mathrm{NH}_{2}$ nanoparticles $\left(\mathrm{SiO}_{2} / \mathrm{GdC} / \mathrm{SiO}_{2}-\mathrm{COOH}\right)$, so that the particles were expected to be surface-modified with carboxyl groups. The SA dissolved in DMF was added to the colloid solution of washed $\mathrm{SiO}_{2} / \mathrm{GdC} / \mathrm{SiO}_{2}-\mathrm{NH}_{2}$ nanoparticles at $35^{\circ} \mathrm{C}$. An initial SA concentration was $0.05 \mathrm{M}$. After $24 \mathrm{~h}$, the $\mathrm{SiO}_{2} / \mathrm{GdC} \mathrm{SiO}_{2-}$ 
$\mathrm{COOH}$ particles were washed by repeating centrifugation, removal of supernatant, addition of water and sonication over three times, which provided the replacement of solvent of colloid solution with water.

\section{Results and Discussion}

\subsection{Morphology of Nanoparticles}

Fig. 1 (a) shows a TEM image of the $\mathrm{SiO}_{2}$ nanoparticles. The silica nanoparticles were quasi spherical and were colloidally stable. They had an average size of $28.6 \pm 12.6 \mathrm{~nm}$. The $\mathrm{SiO}_{2} / \mathrm{GdC}$ nanoparticles exhibited no aggregation during the GdC-coating of $\mathrm{SiO}_{2}$ nanoparticles, which indicated that colloidal stability of $\mathrm{SiO}_{2}$ nanoparticles prevented generation of aggregation. Fig. 1 (b) shows a TEM image of $\mathrm{SiO}_{2} / \mathrm{GdC}$ nanoparticles. The $\mathrm{SiO}_{2}$ nanoparticles were coated with uniform GdC shell. An average particle size and an average shell thickness were $107.0 \pm 23.0$ and $35.9 \pm 4.9 \mathrm{~nm}$, respectively. There was neither uncoated $\mathrm{SiO}_{2}$ nanoparticles nor core-free particles. Fig. 1 (c) shows a TEM image of $\mathrm{SiO}_{2} / \mathrm{GdC} / \mathrm{SiO}_{2}$ nanoparticles. Prior to the TEM observation, the nanoparticles were washed by repeating centrifugation, removal of supernatant, addition of the water and sonication over three times. Only multilayered core-shell particles were observed, and there was neither $\mathrm{SiO}_{2} / \mathrm{GdC}$ core-free silica nor $\mathrm{SiO}_{2}$ shell-free $\mathrm{GdC} / \mathrm{SiO}_{2}$ nanoparticles. An average particle size was $119.0 \pm 39.0 \mathrm{~nm}$. An average $\mathrm{SiO}_{2}$ shell thickness was $8.5 \pm 2.7 \mathrm{~nm}$, according to a high magnification image (a left inset of Fig. 1 (c)). It was confirmed by naked eye that no sedimentation took place for the $\mathrm{SiO}_{2} / \mathrm{GdC}_{\mathrm{SiO}}$ nanoparticle colloid solution. This observation indicated that the $\mathrm{SiO}_{2}$ shell contributed to their colloidal stability.

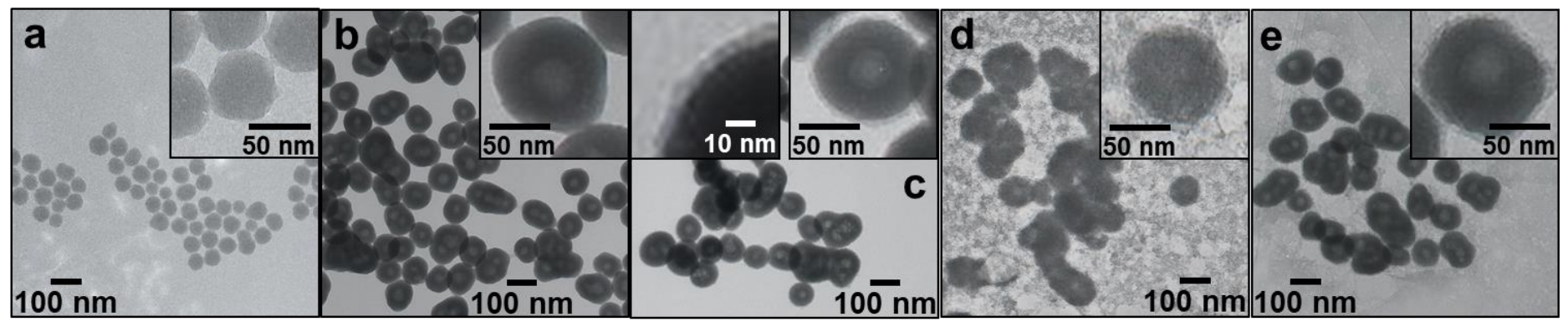

Fig. 1: TEM images of (a) $\mathrm{SiO}_{2}$, (b) $\mathrm{SiO}_{2} / \mathrm{GdC}$, (c) $\mathrm{SiO}_{2} / \mathrm{GdC} / \mathrm{SiO}_{2}$, (d) $\mathrm{SiO}_{2} / \mathrm{GdC} / \mathrm{SiO}_{2}-\mathrm{NH}_{2}$, (e) $\mathrm{SiO}_{2} / \mathrm{GdC} / \mathrm{SiO}_{2}-\mathrm{COOH}$.

\subsection{Surface-Modification}

Fig. 1 (d) shows a TEM image of $\mathrm{SiO}_{2} / \mathrm{GdC} / \mathrm{SiO}_{2}-\mathrm{NH}_{2}$ nanoparticles. Their multilayered core-shell structure of $\mathrm{SiO}_{2} / \mathrm{GdC} / \mathrm{SiO}_{2}$ nanoparticles was not damaged even with the surface-modification process using APMS. Many gel networks were also generated. Since the as-prepared $\mathrm{SiO}_{2} / \mathrm{GdC} / \mathrm{SiO}_{2}$ nanoparticles were used for the surface-modification, unreacted TEOS that did not form the $\mathrm{SiO}_{2}$ shells had might been left in the colloid solution. Probably, $\mathrm{SiO}_{2}$ nuclei were generated through hydrolysis and condensation of alkoxide groups of TEOS. Generation of silanol groups through the hydrolysis probably increased the ionic strength. Increased ionic strength has been reported to compress the double layer of colloidal particles [6]. The generation of silanol groups therefore decreased the double-layer repulsion between the nuclei. The increased ionic strength was thus primarily responsible for the aggregation and growth of nuclei in the present system, which formed the gel networks. A reaction between salicylaldehyde and amino group provides yellowish coloration of solution [7]. In the present work, the presence of amino groups in solutions was confirmed by the yellowish coloration. Figs. 2 (B) and (b) shows photographs of the $\mathrm{SiO}_{2} / \mathrm{GdC} / \mathrm{SiO}_{2}-\mathrm{NH}_{2}$ nanoparticle colloid solutions prior to and after the addition of salicylaldehyde. The color of the colloid solution turned yellowish after the addition. In the case of the $\mathrm{SiO}_{2} / \mathrm{GdC} / \mathrm{SiO}_{2}$ nanoparticles, no color change took place, as shown in Figs. 2 (A) and (a). Probably, the color change took place by a reaction between salicylaldehyde and amino group. Accordingly, the color change confirmed that amino groups were introduced on the $\mathrm{SiO}_{2} / \mathrm{GdC} / \mathrm{SiO}_{2}$ particle surface, or the $\mathrm{SiO}_{2} / \mathrm{GdC} / \mathrm{SiO}_{2}$ particle surface was successfully surfacemodified with amino groups with the amination process. Fig. 1 (e) shows a TEM image of $\mathrm{SiO}_{2} / \mathrm{GdC} / \mathrm{SiO}_{2}-\mathrm{COOH}$ nanoparticles. Their multilayered core-shell structure of $\mathrm{SiO}_{2} / \mathrm{GdC} / \mathrm{SiO}_{2}-\mathrm{NH}_{2}$ nanoparticles was not damaged even with the surface-modification process using SA. The amount of the gel network remarkably diminished compared to the $\mathrm{SiO}_{2} / \mathrm{GdC} / \mathrm{SiO}_{2}-\mathrm{NH}_{2}$. Its weight was so light compared with the $\mathrm{SiO}_{2} / \mathrm{GdC}_{\mathrm{SiO}}-\mathrm{COOH}$ nanoparticles that some of the gel 
networks did not sediment with the centrifugation process. Consequently, the repeated washing process gradually removed the non-sedimenting gel networks. Figs. 2 (C) and (c) shows photographs of the $\mathrm{SiO}_{2} / \mathrm{GdC}_{\mathrm{SiO}}-\mathrm{COOH}$ nanoparticle colloid solutions prior to and after the addition of salicylaldehyde. The color of the colloid solution turned yellowish after the addition. The color change was slighter than that for $\mathrm{SiO}_{2} / \mathrm{GdC} / \mathrm{SiO}_{2}-\mathrm{NH}_{2}$ nanoparticles. The amino groups were transformed to carboxyl groups by a reaction between the functional groups of SA and the amino groups on $\mathrm{SiO}_{2} / \mathrm{GdC} / \mathrm{SiO}_{2}-\mathrm{NH}_{2}$ nanoparticles, which reduced the amino groups on particles. The reduction provided the slight color change, which indicated successful introduction of carboxyl groups onto particles, or surface-modification of particles with carboxyl groups.

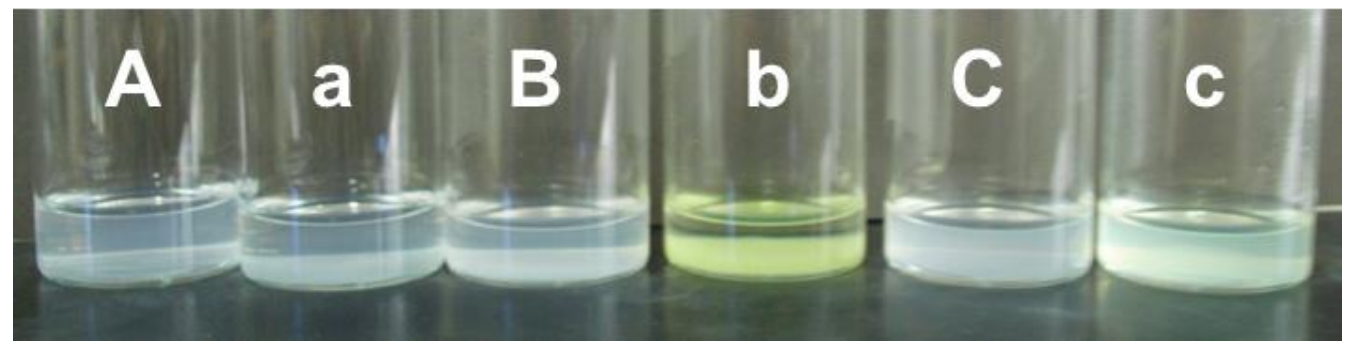

Fig. 2: Photographs of various colloid solutions. (A) and (a): $\mathrm{SiO}_{2} / \mathrm{GdC} / \mathrm{SiO}{ }_{2}$. (B) and (b): $\mathrm{SiO}_{2} / \mathrm{GdC} / \mathrm{SiO}_{2}-\mathrm{NH}_{2}$. (C) and (c): $\mathrm{SiO}_{2} / \mathrm{GdC}_{\mathrm{SiO}}-\mathrm{COOH}$. The samples (A)-(C) and (a)-(c) were prior to and after the addition of salicylaldehyde, respectively.

\section{Conclusion}

Fabrication of multilayered $\mathrm{SiO}_{2} / \mathrm{GdC}_{\mathrm{SiO}}$ core-shell nanoparticles and surface-modification of the multilayered core-shell nanoparticles have been performed. The $\mathrm{SiO}_{2}$ nanoparticles with the size of $28.6 \pm 12.6 \mathrm{~nm}$ fabricated through the sol-gel method were coated with GdC shells by means of the homogeneous precipitation method with the aid of stabilizer PVP, which produced the $\mathrm{SiO}_{2} / \mathrm{GdC}$ nanoparticles that had the average particle size of $107.0 \pm 23.0 \mathrm{~nm}$ and the average $\mathrm{GdC}$ shell thickness of $35.9 \pm 4.9 \mathrm{~nm}$. The $\mathrm{SiO}_{2} / \mathrm{GdC}$ nanoparticles were coated with $\mathrm{SiO}_{2}$ shells by the sol-gel method using the as-prepared $\mathrm{SiO}_{2} / \mathrm{GdC}$ nanoparticle colloid solution, which formed $\mathrm{She}^{\mathrm{SiO}} / \mathrm{GdC}_{2} \mathrm{SiO} \mathrm{O}_{2}$ nanoparticles that had the average particle size of $119.0 \pm 39.0 \mathrm{~nm}$ and the average $\mathrm{SiO}_{2}$ shell thickness of $8.5 \pm 2.7 \mathrm{~nm}$. The $\mathrm{SiO}_{2} / \mathrm{GdC} / \mathrm{SiO}_{2}$ nanoparticle surface was aminated with APMS, and the amino groups of nanoparticle surfaces were transformed to carboxyl groups with SA.

\section{References}

[1] L. Telgmann, M. Sperling and U. Karst, "Determination of gadolinium-based MRI contrast agents in biological and environmental samples: A review," Anal. Chim. Acta, vol. 764, pp. 1-16, 2013.

[2] R. Artali, G. Bombieri, G. B. Giovenzana, M. Galli, L. Lattuada and F. Meneghetti, "Preparation, crystallographic and theoretical study on a bifunctional Gd-AAZTA derivative as potential MRI contrast agent precursor," Inorg. Chim. Acta, vol. 407, pp. 306-312, 2013.

[3] G. Marshall and C. Kasap, "Adverse events caused by MRI contrast agents: implications for radiographers who inject”, Radiography, vol. 18, pp. 132-136, 2012.

[4] Y. Kobayashi, J. Imai, D. Nagao, M. Takeda, N. Ohuchi, A. Kasuya and M. Konno, "Preparation of multilayered silica-Gd-silica core-shell particles and their magnetic resonance images," Colloids Sur. A, vol. 308, pp. 14-19, 2007.

[5] Y. An, M. Chen, Q. Xue and W. Liu, "Preparation and self-assembly of carboxylic acid-functionalized silica," $J$. Colloid Interface Sci., vol. 311, 507-513, 2007.

[6] K. Dimic-Misic, M. Hummel, J. Paltakari, H. Sixta, T. Maloney and P. Gane, 'From colloidal spheres to nanofibrils: extensional flow properties of mineral pigment and mixtures with micro and nanofibrils under progressive double layer suppression," J. Colloid Interface Sci., vol. 446, pp. 31-43, 2015.

[7] F. Cuoq, A. Masion, J. Labille, J. Rose, F. Ziarelli, B. Prelot, J.-Y. Bottero, "Preparation of amino-functionalized silica in aqueous conditions," Appl, Surf, Sci., vol. 266, pp. 155-160, 2013. 